\title{
TRABALHO COM A LINGUAGEM E ENVELHECIMENTO: UMA BUSCA POR RESSIGNIFICAÇÕES DE HISTÓRIAS DE VIDA
}

\author{
Language and aging: a search for resignifications of life stories
}

\author{
Regina Célia Celebrone Lourenço(1), Giselle Massi(2), Roxele Ribeiro Lima( ${ }^{(3)}$
}

\begin{abstract}
RESUMO
Este estudo propõe-se a descrever as vivências de idosos participantes de uma Oficina de Linguagem $(\mathrm{OL})$ que promove discussões orais e a escrita de narrativas autobiográficas. Trata-se de um relato de caso de uma pesquisa qualitativa realizada, por meio de uma entrevista semi-estruturada, com 10 idosos. Todos os sujeitos eram participantes da OL de uma Unidade de Saúde de Curitiba/PR. Os sujeitos relataram que, ao se inscreverem para participarem do grupo, não sabiam exatamente o que era a OL. Entretanto, o convite à escrita de suas histórias de vida os levou a se inscreverem na OL, assim como a necessidade que tinham da convivência em grupo, de compartilhar histórias com outros e incentivo mútuo. A experiência de narrar e escrever suas histórias de vida os fez ressignificar seus posicionamentos em relação ao outro, a eles próprios, bem como aos seus envelhecimentos e a sociedade em que estão inseridos. Por meio da OL, organizaram suas ideias e realizaram o sonho de infância de escrever. Acreditam que o material produzido na OL será lido pelas gerações futuras. Atribuem ao grupo papel fundamental de propiciar tais vivências por meio do apoio que seus membros oferecem uns aos outros. A OL desempenhou uma prática de trabalho de linguagem que proporcionou vivências subjetivas satisfatórias a sujeitos idosos em seus processos de envelhecimentos, promovendo a saúde e a qualidade de vida, no momento da velhice, bem como a realização de sonhos antigos e experiências que dotam a velhice de sentido.
\end{abstract}

DESCRITORES: Linguagem; Idoso; Narrativas pessoais como assunto; Qualidade de Vida.

\section{INTRODUÇÃo}

A literatura indica que, desde tempos remotos, desponta o atrelamento da velhice à decrepitude que se dissemina na sociedade contemporânea, privilegiando o novo e depreciando o velho, por estar pautada no imperativo da produtividade e do consumo. Sujeitos inseridos em uma linha de montagem, como nomeiam Faleiros e Justo (2007), os quais não deveriam ser reduzidos a uma homogeneização discursiva acerca do que seja o belo e o bom ${ }^{1}$.

Estes ditos depreciativos engendrados em uma cultura que desvaloriza o velho e cultua o novo afeta os idosos dela participantes que, ao constatarem não possuir os adjetivos preconizados nesta

\footnotetext{
(1) Universidade Tuiuti do Paraná - UTP, Curitiba, PR, Brasil.

(2) Universidade Tuiuti do Paraná - UTP, Curitiba, PR, Brasil.

(3) Universidade Tuiuti do Paraná - UTP, Curitiba, PR, Brasil.

Conflito de interesses: inexistente
}

sociedade, subjetivamente dela se excluem. Para este argumento, o questionamento de Goldfarb é esclarecedor:

Cabe então perguntarmos sobre a particular subjetivação do 'ser velho' em um momento histórico onde a velhice perdeu as atribuições próprias da sociedade tradicional, e onde parece ser mais uma 'invenção social', uma categoria na qual é possível depositar tudo o que remete à inutilidade, à dor, à finitude e à morte e que é assim expulsa em direção às bordas, marginalizada ${ }^{2}$.

A questão que se coloca é que, diante das estatísticas do IBGE ${ }^{3}$ que estima em 32 milhões o número de idosos em 2025, urge a criação de práticas junto a eles, que sejam perpassadas por perspectivas teóricas que privilegiam a subjetividade, porque dos cuidados do envelhecimento fisiológico, a área médica ocupa-se com rigor. Atribui-se à subjetividade o estatuto do imensurável, 
de inapreensível por demonstração empírica. O material psíquico que engendra o Homem referente aos seus sentimentos e emoções, como medos, ansiedades, inseguranças, prazeres, infelicidades e satisfações, constituem a subjetividade de cada ser humano ${ }^{4}$.

O trabalho com a linguagem favorece vivências subjetivas e a autoria da própria vida, como aponta Medeiros (2006) $)^{5}$, e o engendramento de um sujeito responsivo e responsável frente ao existir.

Salienta-se que os discursos estabilizados na contemporaneidade acerca da velhice estão atrelados a decrepitude, como posição discursiva que promove aridez na vida dos idosos, e que são passíveis de serem subvertidos e ultrapassados por trabalhos com a linguagem. Estes, por sua vez, despontam neste artigo como derivativos poderosos que oportunizam velhos a tecerem novos enunciados acerca do que seja envelhecer, e que os favoreça a extrair luz de sua desgraça, nas palavras de Sigmund Freud (1930/1974) ${ }^{6}$.

O grupo da Oficina da Linguagem tem como fim específico a escrita de histórias de vida, proporcionando o encontro com o outro à medida que os idosos se reúnem para concretização do objetivo da escrita e publicação de suas histórias de vida. O grupo constitui-se como espaço de interlocução à medida que insere os idosos em uma arena de vozes sociais e um agitado balaio de vozes, nos termos bakhtinianos ${ }^{7}$, que produz conflito e convoca negociações. O grupo, então, desponta como propiciador da exposição das diferenças, e estas convocam o retorno do olhar para si mesmo. Espaço que representa a marca do coletivo e permite o conhecimento sobre si e os outros, levando ao desenvolvimento dos participantes. Esta diversidade discursiva possibilita a quem vive o processo de envelhecimento perceber em si e no outro tanto a singularidade de cada pessoa que envelhece como a multiplicidade de envelhecimentos. Neste sentido, afirma Bakhtin:

"Quando compreendemos o outro, fazemos corresponder à sua palavra uma série de palavras nossas; quando nos fazemos compreender pelos outros, sabemos que às nossas palavras eles fazem corresponder uma série de palavras suas"6.

Inspiradas neste dito bakhtiniano, apontou-se, neste artigo, situações grupais como favorecedoras do encontro com outros que nos (re)constituem à medida que nos favorecem um olhar sobre nós mesmos e, no caso específico do grupo da Oficina da Linguagem, o encontro dos idosos com eles próprios e com os outros membros do grupo. Isto porque, como apontam Marques e Seminotti ${ }^{8}$, os grupos têm uma força e uma capacidade ímpar de mobilizar sentimentos e atitudes que se revestem de novas esperanças quanto a possibilidades de realizações individual e social. Estes autores argumentam que um grupo tem possibilidades terapêuticas, as quais, se bem aproveitadas, podem levar a mudanças de estilos de vida, atitudes, visão de Homem, mundo e sociedade ${ }^{8}$. Não se trata de uma terapia de grupo para idosos, porque não é este o objetivo da Oficina, mas ao se trabalhar com o que constitui o humano, a linguagem, é impossível deixar os efeitos terapêuticos de fora. Estas são constatações também de Olmos $(2004)^{9}$, que relata experiências em oficinas com idosos. No sentido dos efeitos terapêuticos de linguagem na subjetividade, já adiantando na apresentação dos resultados dessa pesquisa, um idoso do grupo declara que a Oficina da Linguagem arrumou a sua vida, as suas ideias e opiniões ${ }^{9}$.

Neste sentido, o trabalho desenvolvido no grupo da Oficina da Linguagem objetiva propiciar bons encontros aos participantes. Visa oportunizar vivências com a linguagem oral e escrita, que possibilite a negociação com seus conflitos e mal estares engendrados pelas marcas da civilização em sua subjetividade. Ao negociarem com estas vozes destoantes entre si, criam com a velhice costuras originais e diferentes roupagens, como brilhantemente elucida Mucida (2006) ${ }^{10}$, o que Ihes aufere saúde mental e física, além de qualidade de vida. Neste artigo, relata-se o que levou 10 velhos a procurarem uma Oficina de Linguagem, e as conquistas subjetivas advindas desta experiência, na ressignificação de suas histórias de vida.

\section{APRESENTAÇÃO DO CASO}

A pesquisa aqui apresentada foi aprovada pelo Comitê de Ética da Universidade Tuiuti do Paraná, conforme número 102/08. Ela foi realizada com 10 idosos entre 60 e 86 anos, de ambos os sexos e sem dificuldades neurológicas vinculadas à linguagem.

O grupo da Oficina da Linguagem, vinculado ao Programa de Mestrado e Doutorado em Distúrbios da Comunicação da Universidade Tuiuti do Paraná, desponta como prática de trabalho com a subjetividade de idosos, que promove situações de interação como lugar privilegiado da linguagem. Este grupo encontrou-se alocado dentro da Unidade de Saúde da Praça Ouvidor Pardinho, que é referência ao atendimento a idosos na cidade de Curitiba, entre os anos de 2003 a 2012. Atualmente, a partir de 2013, desenvolve suas atividades na própria Universidade a que este programa vincula-se. $\mathrm{O}$ grupo reúne-se semanalmente, com encontros de 
uma hora e meia cada, com a proposta de convocar velhos a escreverem suas histórias de vida.

Os critérios de inclusão na pesquisa foram pessoas acima de 60 anos que se inscreveram no grupo e nele permaneceram durante o ano de 2010.

Os critérios de exclusão foram sujeitos acima de 60 que não apresentaram condições cognitivas de escrever histórias de vida.

O método utilizado foi o da pesquisa qualitativa que lida com significados e valores de cunho pessoal e particular, e a coleta de dados foi feita a partir de uma entrevista semi-estruturada. Neste sentido, Moreira (2006) ${ }^{11}$ sustenta que a entrevista semiestruturada parte de um roteiro que inclui os temas a serem discutidos na pesquisa, mas deixa o participante livre para responder a eles sem obedecer à ordem das perguntas e sem precisar limitar-se estritamente ao que foi perguntado, no caso: "O que você veio procurar em uma Oficina da Linguagem?" aos 10 idosos nela presentes, no dia 14/03/2011. Os mesmos aceitaram participar da pesquisa e assinaram os termos de consentimento livre e esclarecido.

As respostas de cada participante foram sendo anotadas concomitantemente pelas autoras. Posteriormente, foram analisados os conteúdos das respostas, no que se refere ao que estes 10 idosos pretendiam ao se inscreverem como participantes em uma Oficina de Linguagem e o que lá encontraram.

Para a leitura e organização dos dados, foram estabelecidas categorias de análise das falas dos sujeitos, ao que se refere à pergunta de pesquisa, ou seja, o que levou os idosos desta pesquisa a se inscreverem uma Oficina de Linguagem.

As respostas que os idosos deram a esta pergunta foram categorizadas em quatro itens, referentes aos conteúdos recorrentes nas suas falas, que são:

$1^{\circ}$ - Ao se inscreverem, não sabiam exatamente o que era uma Oficina de Linguagem.

$2^{\circ}$ - O convite à escrita de suas histórias de vida os levou a se inscreverem na Oficina.

$3^{\circ}$ - A necessidade da convivência em grupo, de compartilhar histórias com outros e incentivo mútuo, os fez procurar o grupo.

$4^{\circ}$ - As Mudanças provenientes da participação em uma Oficina de Linguagem.

Os participantes da pesquisa autorizaram a divulgação de suas respostas. Estas foram transcritas tais quais narradas por eles, sem correções e inferências ortográficas por parte das pesquisadoras. Suas respostas foram lidas e endossadas por eles.
Ainda, a título de esclarecimento metodológico, como referido no inicio deste artigo, os idosos foram capturados por ditos como escrita de histórias de vida, convivência com pares, nos cartazes espalhados no início de cada ano pela Unidade de Saúde, que anunciam a existência da Oficina e convocam participantes para o grupo. Estes ditos convidavam à narração de experiências pessoais, o trabalho com textos orais, escrever histórias e reencontrar amigos.

\section{RESULTADOS}

Serão expostos, a seguir, alguns ditos dos idosos à pergunta: $\mathrm{O}$ que vocês vieram procurar em uma Oficina de Linguagem? E as respostas dadas a tal questão foram analisadas de acordo com os critérios metodológicos explicitados. Os sujeitos estão referidos pelas iniciais de seus nomes, a fim de preservar suas identidades.

$1^{\text {a }}$ categoria de análise: Ao se inscreverem, não sabiam exatamente o que era uma Oficina de Linguagem.

M. "Ao ouvir o termo Oficina da Linguagem me perguntei: O que será isto?"

V. "Com relação à Oficina de Linguagem, queria falar uma coisa, e primeiro é o termo oficina. Oficina pra mim é coisa quebrada, e quando vi este dito no cartaz disse para mim mesma que não tinha nada quebrado em mim e não me inscrevi. Aí passou uns tempos e pensei: sabe de uma coisa, acho que tem algo quebrado sim e vim e amei. Aí quando vim me perguntaram o que eu vim fazer ali. Disse sobre a Oficina e logo veio o que tá quebrado: Acho que a língua! Estou consertando."

MA: "Eu já falei aqui pros veteranos que sempre tive vontade de escrever e ler histórias, só que não tinha escola. Um dia vi no painel convidando pra Oficina da Linguagem e imaginei que era pra educar a voz. Cheguei aqui na primeira reunião, a gente bateu papo com a Giselle, tanto papo que ela veio: "vocês não gostariam de escrever? Acho que ela pensou: É melhor eles escrevendo e calados. Eu presumi assim."

Nestes ditos acima, os idosos explicitam que não sabiam do que a Oficina tratava, ao lerem o cartaz pela primeira vez; que a língua estava quebrada e tinha que consertá-la e que no grupo, à semelhança do social que pouco quer saber dos idosos, a coordenadora também queria que ficassem com a boca fechada. Esta colocação evidencia o engendramento dos idosos pelos discursos da cultura que deprecia o velho e eles os reproduzem no grupo.

Ainda acerca da língua quebrada da idosa do grupo, esta refere que, a partir da sua participação 
neste, está consertando sua língua, ao impor menos seus pontos de vista em casa e ouvir a opinião de seus familiares, coisa que não fazia anteriormente às suas vivências na Oficina.

\section{$2^{\mathrm{a}}$ categoria: $\mathrm{O}$ convite à escrita de suas histórias de vida levou os idosos a se inscreverem na Oficina.}

T: "Toda a vida tive vontade de escrever, sempre gostei muito de escrever, tenho um monte de cadernos de coisas antigas, tudo o que eu achava bonito, uma frase, eu colocava por escrito. Aí, então, eu pude realizar este sonho na Oficina. Aqui eu não vou deixar de vir, pode estar chovendo, estar frio... eu adoro!"

ME: "É uma maneira de expressar tudo o que a gente tem na cabeça. De que maneira, se boa ou não, mas chega uma hora que, em conjunto, percebe alguma coisa boa para transmitir. Acho que então pra mim isso aqui é uma maravilha. É um Oasis. E quero."

MA: "A Oficina da Linguagem, no meu ponto, é você, o seu pensamento você trás para o seu linguajar, e aí você transfere para o papel porque o linguajar pode ser esquecido e a escrita jamais. $O$ que nós falamos aqui chegamos metade em casa esquecemos, mas o que tiver escrito não. Esse é o valor da Oficina da Linguagem, trazer o pensamento em escrita."

E. "Então é assim, quando vim aqui eu comecei a sonhar. Eu sempre tive o sonho de escrever a minha história de vida. Tenho muitas memórias, lembranças, e não sei por onde começar a escrever a minha história de vida. Então, eu já estou merecida, porque estou escrevendo minha história."

$\mathrm{M}$ : "Na verdade é assim, no comecinho, quando me falaram o termo Oficina da Linguagem, achei que era só de falar, falar, falar e só. Eu sempre tive um sonho íntimo e pessoal de escrever. Quando eu cheguei aqui e vi que não era só conversar mas sim escrever, eu me realizei. Foi algo que veio de encontro a coisas que já tinha também. Que posso complementar."

Estas narrativas evidenciam o papel que a escrita de suas histórias de vida assumiu na ressignificação subjetiva dos velhos, ao poderem realizar este sonho antigo, deixarem suas memórias registradas e imortalizadas através dos tempos vindouros.

\section{$3^{\text {a }}$ categoria: A necessidade da convivência em grupo, de compartilhar histórias com outros e incentivo mútuo, os fez procurar a Oficina da Linguagem.}

$\mathrm{TH}$ : "A gente sente falta das pessoas, o entrosamento é importante."
T. "O melhor de tudo que a gente sente falta das pessoas. Isso acho o mais importante. Hoje em dia ninguém se preocupa mais em dar bom dia, boa tarde, e a gente sente falta disso, de conversar, de uma companhia, de entrosamento...nós superamos as dificuldades que temos cada um ajudando o outro. Vivendo e aprendendo!"

M. "Eu estou escrevendo a minha história de vida, e ouvir as histórias das pessoas do grupo, me incentiva a escrever a minha."

Conforme teorizado neste trabalho, estes enunciados dos idosos reafirmam o papel do outro na ressignificação de suas histórias de vida, encenado pelo grupo e por seus membros.

\section{$4^{\mathrm{a}}$ categoria: Mudanças provenientes da participação em uma Oficina de Linguagem.}

TH: "Eu acho que a Oficina aqui está mudando muito os meus conceitos. A gente trás, todo mundo trás, neto, velho, que pessoa de idade é pra ficar ali sem fazer nada. Eu acho que a gente aqui está mostrando muita coisa, não no sentido que dão aí, que o velho tem que ficar velho, não, tem outras coisas, porque você vê na mídia as coisas que o velho tem que dançar, tem que fazer isto e não aquilo. Não, nós temos ainda muitas coisas pra mostrar, pra fazer, porque essa juventude que tem aí, se você olhar, não é igual a nossa, nós deixamos eles no chinelo, porque a gente sabe muita coisa. A gente ainda tem muita coisa para fazer."

\section{A.A "Oficina desenvolve talentos"}

J.A "Oficina de Linguagem até pra falar é a nossa vida, nossa palavra, nosso ser, o quanto arrumou. É Oficina mesmo, porque arrumou não só o nosso ser, mas nossas ideias, conhecimentos. Aprendi muito, tenho muito orgulho e pretendo largar nunca mais. Só quando morrer agora."

Y. "Na Oficina eu aprendo na velhice e vou deixar para os outros as minhas histórias."

Estes depoimentos corroboram o que foi sustentado neste trabalho, o papel que o trabalho de linguagem praticado na Oficina da Linguagem exerce na retificação simbólica dos velhos em relação às suas velhices e aos outros com quem se relacionam como cidadãos, como sujeitos singulares e coletivos que são.

Os dados deste estudo evidenciam os efeitos terapêuticos na subjetividade de idosos frequentadores de grupos no momento do envelhecimento, conforme apontados por Olmos (2004) $)^{9}$ e Marques e Seminotti $(2002)^{8}$, assim como promovem saúde mental, física e qualidade de vida, características essenciais de serem vivenciadas na velhice, como sustenta Mucida $(2006)^{10}$. 


\section{DISCUSSÃO}

Retomando o objetivo deste estudo, que foi apresentar o que 10 pessoas acima de 60 anos pretendiam ao se inscreverem como participantes em uma oficina de linguagem, e os efeitos da escrita e publicação de suas histórias de vida em sua subjetividade, constatou-se que a maioria deles não sabia o que era e nem o que se fazia na Oficina de Linguagem ao nela se inscreverem.

Cabe aqui esclarecer, no auxílio da compreensão do leitor de como surgiu a Oficina da Linguagem, no ano de 2003, que a fonoaudióloga que o fundou (a Giselle citada na resposta de um deles), não direciona as atividades, desde o surgimento do grupo, na direção da escrita de histórias de vida. Em seu início, o grupo intitulava-se Oficina da Voz. O trabalho voltava-se mais para aspectos orgânicos e fisiológicos da voz. Entretanto, no andar da carruagem, a trilha apontada pelos idosos dela participantes, na época, foi a do desejo de narrarem e serem escutados em suas singulares histórias de vida, desejo este acolhido pela coordenadora, que é perpassada pela filosofia de linguagem de Bakhtin. Fazendo uma brincadeira com o sentido das palavras, hoje é possível afirmar que se trata de uma Oficina de avós que têm A-VOZ. Estes avós desejavam sim trabalhar a voz, mas as metafóricas.

Desta forma, de uma Oficina que se propunha ao trabalho com a voz orgânica, desponta um trabalho com as vozes metafóricas, a partir de relatos de histórias de vida, as quais recebem o apelo de serem registradas pela escrita. Estes escritos convertem-se em livros, que são publicados anualmente, com noites de autógrafos em variados espaços culturais de Curitiba. Esta posição subjetiva de reconhecimento social e olhar do outro, aufere aos idosos lugares de escritores e autores de suas histórias de vida, que segundo seus relatos, é um sonho que trazem junto a si desde a sua mocidade.

A Oficina desponta, neste artigo, como a oportunidade destes idosos realizarem um sonho do passado, que é o da escrita, como principal motor que os fisga no cartaz que convoca à participação na Oficina da Linguagem. Em semelhança aos idosos que são convocados pelo cartaz e declaram não saberem do que este grupo tratava até nele se inserirem, sua coordenadora também o inicia pensando tratar-se de outra coisa. É juntamente a eles que se constroem novos sentidos em uma arena de embate das heterogêneas vozes que nos constituem, que é condição de seres engendrados pela linguagem que se é.

Esta arena de embate e agitado balaio de vozes sociais, nos termos bakhtinianos, são vivenciados em situação de grupo. O encontro com o outro que acrescenta, conflita, interroga, guerreia, os projeta para além de si mesmos, na criação de medidas que os façam extraírem luz de suas existências. Inevitavelmente, ao serem engendrados por discursos sociais que desmerecem o velho e tudo o que a ele concerne, o grupo da Oficina da Linguagem constitui-se como oportunidade de construção de inusitados discursos acerca do envelhecimento pelos velhos dela participantes. Devido a este lugar que conquistaram e constroem ininterruptamente, é que os idosos atribuem à participação em um grupo de velhos um dos motivos pelos quais se inscreveram na Oficina da Linguagem. A necessidade da convivência em grupo, de compartilhar histórias com outros e incentivo mútuo, os fez procurar a Oficina, segundo relatam.

Ao referirem o que mudou em suas vidas, como decorrência da participação nessa Oficina de Linguagem, despontam atributos como possibilidade de desenvolver talentos, mostrar para a sociedade que o idoso sabe muita coisa, auxiliando desta maneira a ressignificar seus conceitos acerca do envelhecimento. Narram que a Oficina consertou, arrumou suas ideias e conhecimentos, que aprenderam muito nela e que não pretendem largá-la nunca mais, só quando morrerem. Declaram que desejam transmitir estes aprendizados para outros, na forma de relatos escritos.

Estas retificações subjetivas nos modos dos velhos da Oficina analisarem seus processos de envelhecimento ancoram-se nos ditos de Teixeira $(2003)^{12}$, que o homem se constrói no social e, neste sentido, o grupo da Oficina da linguagem é o espaço social, onde velhos têm a oportunidade, a partir da reconstituição narrativa de suas histórias de vida, de "tomarem consciência das nuanças de seu percurso, podendo ressignificar suas experiências, sair de uma posição de alienação frente à História, situando-se como agente de sua vida e coletividade".

\section{CONCLUSÃO}

Constatou-se, neste estudo, que a experiência de sujeitos em grupos que se propõem ao trabalho com os aspectos subjetivos do envelhecimento pela linguagem escrita, como é o caso da Oficina da Linguagem, oportuniza-os a viver a fase da vida denominada de velhice, terceira idade, quarta idade, melhor idade, seja lá quais forem as nomenclaturas utilizadas na tentativa de nomear o inominável, com qualidade de vida e vivências dotadas de sentido. Pela possibilidade que o grupo oferece aos sujeitos que dele participam de ocuparem lugares de autores de suas histórias, é que apresentou-se tal grupo como espaço privilegiado de (re) significação de 
histórias de vida. Os idosos deste estudo puderam narrar e escrever suas narrativas autobiográficas por estarem inseridos em um grupo direcionado aos aspectos subjetivos do envelhecimento em detrimento ao enfoque sobre os desgastes do corpo biológico ocasionados pelo passar dos anos. A concepção dialógica de linguagem que orienta o programa de mestrado e doutorado em Distúrbios da Comunicação da Universidade Tuiuti do Paraná não concebe o envelhecimento como doença que precisa ser curada com práticas ortopédicas que visem à normalização ou cura da velhice, mas a assume como processo de desenvolvimento subjetivo e psíquico enquanto o idoso ainda estiver vivo.

A partir da experiência dos idosos em um grupo com esta perspectiva de linguagem, que prioriza as satisfações subjetivas que ainda são possíveis de serem vivenciadas no momento do envelhecimento, é que conseguem atribuir sentido ao envelhecimento e usufruir desta fase denominada pelo discurso contemporâneo como a ultima da vida, com a realização de sonhos e projetos postergados em momentos anteriores de suas existências.

Concluímos, a partir das falas dos idosos deste estudo, que estes puderam, a partir de vivências de linguagem propostas pelo grupo da Oficina da Linguagem, (re) significar as suas histórias em relação à velhice e à vida, contrariando os discursos contemporâneos que desmerecem $\mathrm{o}$ velho $\mathrm{e}$ enaltecem o que é belo e novo.

A escrita das próprias histórias de vida insere os idosos deste estudo na sociedade e lhes aufere lugar de escritores, o que vai na contramão de uma sociedade que exclui seus velhos e os lança à margem.

Os resultados deste estudo sugerem a viabilização de práticas junto a idosos, que contemplem os aspectos subjetivos do envelhecimento em uma sociedade com práticas eminentemente voltadas à reparação dos desgastes do corpo biológico.

\begin{abstract}
To describe the experiences of elderly participants in a Language Workshop (LW) that stimulates discussion and writing through autobiographical narratives. A case report of a qualitative study which was performed a semi-structured interview with 10 elderly people. All subjects were participants of the LW from a health unit center of Curitiba/PR. The subjects reported that had not knowledge about the LW before the moment of their application. However, the invitation to write their life stories as well as the contact with other participants, the sharing of stories and the mutual encouragement motivated them to take part of the LW. The experience of writing and narrating their life stories made them reframe their positions relative to each other as well as their aging process into the society where they are inserted. Through the LW, they developed their talents; they changed their ideas and performed their childhood dream of writing. The subjects believe that the material produced in the LW will be read for future generations. Participants believe that the LW has an important role to provide such experiences by supporting for each member. The LW showed a practical way of language work that provides satisfactory subjective experiences for elderly subjects in their processes of aging. The LW can promote health and quality of life for aging people, and the realization of dreams and old memories that bring a new sense for aging.
\end{abstract}

KEYWORDS: Language; Aged; Personal Narrative as topic; Quality of Life.

\section{REFERÊNCIAS}

1. Faleiros NP, Justo JS. O idoso asilado: a subjetividade intramuros. Rev Bras Geriatr Gerontol. 2007;10(3):1-15.

2. Goldfarb DC. Corpo, tempo e envelhecimento. São Paulo: Casa do Psicólogo. 1998.

3. IBGE. Distribuição da População por sexo, segundo os grupos de idade. http://www.censo2010. ibge.gov.br/sinopse/webservice/; 2010 [cited 2011 05/10].

4. Roudinesco,E.Por quê a Psicanálise?Rio de Janeiro:Jorge Zahar,2000.

5. Medeiros CM. O sujeito bakhtiniano:um ser de reposta. Revista da faculdade do Seridó. 2006;1(0):1-7.

6. Freud S. O Mal-Estar na Civilização (1930/1974). Standard Brasileira das obras psicológicas 
completas de Sigmund Freud ed. Rio de Janeiro: Imago; 1974.

7. Lourenço RCC. A escrita de narrativas autobiográficas no processo de envelhecimento. Rev soc bras fonoaudiol. 2010;15(1):159.

8. Marques JC, Seminotti NO. O grupo como esperança renovada e construção da cidadania. Psicologia Argumento. 2002;20(31):11-9.

9. Olmos JRD. Histórias de vida, marcas de uma vida - Re-apropriação da história pessoal de idosos
- Relato de uma experiência. Revista da SPAGESP - Sociedade de Psicoterapias Analíticas Grupais do Estado de São Paulo. 2004;5(5):71-6.

10. Mucida A. Velhice: Que história se escreve, se conta, se escuta? Periódico. 2006;VII(11):18-20.

11. Moreira $\mathrm{H}$. Metodologia da pesquisa para o professor pesquisador.Rio de Janeiro:DP\&A,2006.

12. Teixeira LC. Escrita autobiográfica e construção subjetiva. USP. 2003;14(1):37-64.

http://dx.doi.org/10.1590/1982-021620148013

Recebido em: 29/04/2013

Aceito em: 02/09/2013

Endereço para correspondência:

Regina Célia Celebrone Lourenço

Av. Sete de Setembro, 357 ap 10

Curitiba - PR - Brasil

CEP: $80050-100$

E-mail: recelebrone@terra.com.br 